\title{
Lateral vibration analysis of continuous bridges utiliz- ing equal displacement rule
}

\section{Abstract}

The application of equal displacement rule simplifies the evaluation of lateral displacement demand forSDOF system. For complex multi-degree-of-freedom (MDOF) structures such as continuous bridge systems, however, it requires more investigations. In this paper, a comprehensive parametric study of the ratio of maximum inelastic displacement to maximum elastic displacement for typical continuous bridges is performedto advance the application of equal displacement rule to MDOF systems. Particurlarly for the bridges with long periods, this adapted methodlogy is further simplified. It is concluded that equal displacement rule of MDOF is applicable to continuous bridges when the periods of the main modes are no less than the limiting period, which usually serves as an indication to the level of inelastic deformation for a bridge subjected to an earthquake.

\section{Keywords}

\author{
Biao Wei ${ }^{\text {a }}$ \\ Ye Xia ${ }^{b, *}$ \\ Weian Liu ${ }^{c}$ \\ a School of Civil Engrg., Central South Uni- \\ versity, Changsha, China \\ ${ }^{\mathrm{b}}$ Dept. of Civil \& Environ. Engrg., Rutgers, \\ The State University of New Jersey, Piscata- \\ way, NJ 08854, USA \\ ' Dept. of Strut. Engrg., Univ. of California, \\ San Diego, CA 92093, USA \\ Received in 21 Nov 2012 \\ In revised form 08 May 2013 \\ * Author email: xiaye.cee@rutgers.edu
}

Equal displacement rule, limiting period, continuous bridges, simplified seismic analysis, displacement demand

\section{INTRODUCTION}

The performance-based seismic design philosophy has been sufficiently developed to design a structure system to withstand a pre-defined level of damage under a pre-defined level of earthquake intensity. Displacement-based seismic design is an efficient and accurate method to achieve the performance-based seismic design philosophy, and it has been proposed and developed in recent years (Kowalsky, 2002; Jameel, Islam, Hussain, et al., 2013). In this methodology, the displacement demand of the designed structure should be close to the target displacement, which reflects the predefined level of damage of earthquake intensity. Therefore, to obtain the displacement demand of structure is an important step. Although analytical methods are widely utilized to calculate the displacement demand of structure, the analysis processes of currently available methods are relatively complex (Chopra and Goel, 2002; Wei, 2011; Akhaveissy, 2012). Hence, it is desired to develop a simplified method herein to obtain the displacement demand to facilitate displacement-based seismic design. 
Equal displacement rule is considered to be an efficient and accurate mechanism to estimate the displacement demand for elastoplastic SDOF systems (Clough and Penzien, 2003; Bayat and Abdollahzadeh, 2011). For elastoplastic SDOF structure, which generally satisfies equal displacement rule, the inelastic displacement demand obtained by Nonlinear Time History Analysis (NTHA) is very close to the elastic displacement demand obtained by Response Spectrum Analysis (RSA). Hence, the elastic displacement demand can represent the true elastoplastic displacement demand, resulting in the simplified calculation process of displacement-based seismic design.

Traditional equal displacement rule is considered applicable to SDOF structures when the according fundamental period is not less than a defined value (Clough and Penzien, 2003). In recent years, equal displacement rule has been further developed and more factors are taken into consideration. Efforts are dedicated since 1960s to propsing and studying a displacement correction factor $C$, which is equal to the ratio of the maximum inelastic displacement to maximum elastic displacement for SDOF systems subjected to seismic excitation (Veletsos and Newmark, 1960; Newmark and Hall, 1969; Riddell et al. 1989; Miranda, 2000). Therefore, maximum inelastic displacement could be approximately obtained by multiplying its elastic counterpart by the factor $C$. Despite of the inconsistent expressions in different literatures, $C$ is approximately equal to 1 for when the target SDOF has a long fundamental period.This finding is definedas to equal displacement rule.

In essence, the previous researches, however, are aimed at investigating SDOF or equivalent SDOF systems. There is little reported study focusing on the lateral deformation of continuous bridges, particularly for irregular bridges with significant higher modes (Isakovic and Fischinger, 2006). In addition, the elastoplastic displacement demand of NTHA is often found to be close to the elastic displacement demand of RSA during traditional seismic design of some continuous bridges. Therefore, it is necessary to study whether the equal displacement rule is still applicable to the MDOF systems.

The objective of this paper is to quantify the application conditions of the equal displacement rule in MDOF bridge systems through a comprehensive parametric study on the ratio of maximum inelastic to elastic displacement in transverse direction for typical continuous bridges. The application of equal displacement rule simplifies the evaluation of lateral displacement demand of many continuous bridges subjected to earthquakes and provides the basis for their simplified displacement-based seismic design.

\section{EQUAL DISPLACEMENT RULE OF SDOF}

In effort to extend equal displacement rule from SDOF to MDOF system, two key parameters affecting equal displacement rule of SDOF system are introduced accordingly: i) the displacement correction factor $C$, and ii) the limiting period $T_{l}$.

There are many expressions available for the displacement correction factor, and the equation of displacement correction factor $C$ from Miranda (2000) is validated to have better precision by some researchers and is given by

$$
C=\left[1+\left(\frac{1}{\mu}-1\right) \cdot \exp \left(-12 T \mu^{-0.8}\right)\right]^{-1}
$$

Latin American Journal of Solids and Structures 11(2014) 075 - 091 
where $T$ is the period of SDOF, $\mu$ is its displacement ductility demand. Figure 1 provides the development of $\mathrm{C}$ in terms of $\mathrm{T}$ for different $\mu$ scenarios, 1.5, 3.0, 6.0, and 9.0respectively,. In this study, the structural damage level is related to $\mu$, where values (from low to high) approximately indicate the slight damage state, the moderate damage state, the severe damage state, and the collapse state respectivelyfor reinforced concrete piers of continuous bridges (Xia et al. 2013).

As observed from Fig.1, factor $C$ is approaching to 1 as period $T$ elongates irrespective of displacement ductility. Note that the limiting period $T_{l}$ that divides the region where the equal displacement rule is not applicable from the region where this approximation is applicable depends on the level of ductility. In general, $T_{l}$ increases as $\mu$ increases. If $C$ is equal to 1 , it is the rigorous equal displacement rule, however, the value of $T_{l}$ will be too large and the corresponding equal displacement rule will not applicable to any structures. Note that the error of $5 \%$ is nornally acceptable for seismic design. When $C$ is equal to 1.05, equal displacement rule is approximately considered appropriate, and the correlation between $T$ and $\mu$ is shown in Fig.2. Through curve-fitting process, the equation of the limiting period $T_{l}$ is determined by

$$
T_{l}=0.4529 \ln \mu+0.0323
$$

When the period $T$ of SDOF is not less than $T_{l}$, equal displacement rule is satisfied. As opposed to the traditional equal displacement rule (Clough and Penzien, 2003), the limiting period $T_{l}$ herein is not a constant value, and it is highly dependent on different levels of structure ductility demand. Therefore, the traditional equal displacement rule could be treated as a special case of Eq.(2), which will be thoroughly presented in the following section. Note that equal displacement rule is based on $C$ is equal to 1.05, and equal displacement rule will be more rigorous if $C$ is less than 1.05 .

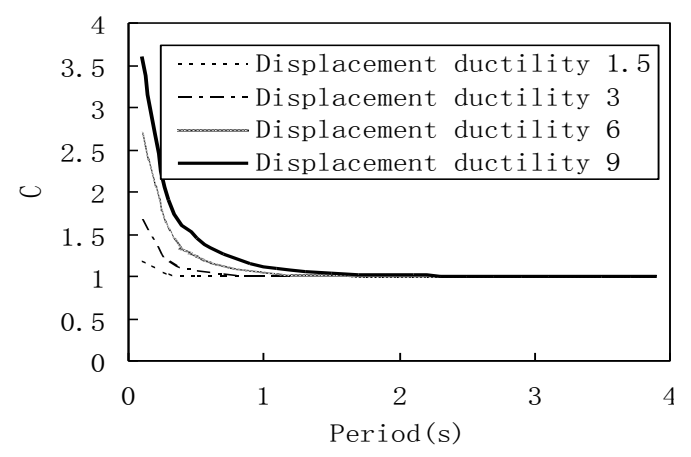

Figure $1 C$ related to different period and displacement ductility of SDOF 


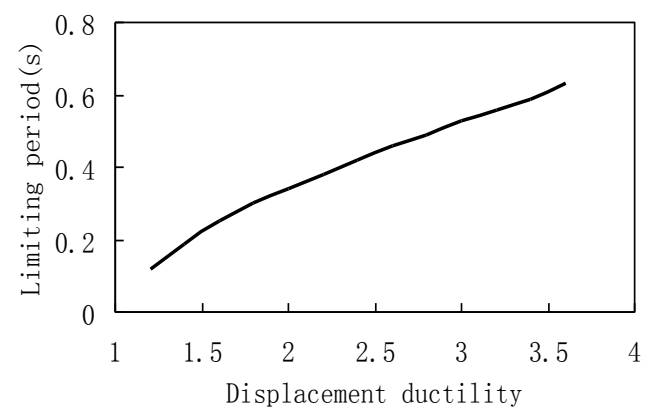

Figure 2 Limiting period of equal displacement rule of SDOF

\section{EQUAL DISPLACEMENT RULE OF CONTINUOUS BRIDGES}

The objective of this section is to present the results of a comprehensive statistical study of the ratio of maximum inelastic displacement to maximum elastic displacement for typical continuous bridges subjected to earthquakes in the transverse direction, and thus to extrapolate equal displacement rule of SDOF to MDOF.

\subsection{Typical continuous bridge structures}

The continuous bridges are widely used in highway and railway [16-17]. Figure 3 provides a $4 \times$ $40 \mathrm{~m}$ continuous bridge configuration with girder and column section properties listed in Table 1. Multi-bearings are laterally set on the top of each column and abutment. Bearings on columns and abutments are all laterally guided except for one laterally fixed on the side column. The arrangement of bearings, which is widely adopted in practical bridge design, prevents abutments with poor ductility from severe earthquake damage.

The displacement ductility demand $\mu_{e}$ of pier is given by

$$
\mu_{e}=\frac{\Delta_{e}}{\Delta_{y}}
$$

In Eq.(3), $\Delta_{e}$ is the elastic displacement of pier obtained by elastic analysis method, i.e., response spectrum analysis (RSA), while $\Delta_{y}$ is the yield displacement of pier assumed as one cantilever column.

Note that, as for bridges with piers of different heights, the moment exists at the top of pier due to the inconsistent deformation of piers and the restriction of girder, therefore, $\Delta_{y}$ obtained by assuming each pier as one cantilever column may be not the true yield displacement. In addition, $\Delta_{e}$ may be not the true displacement (approximately true displacement when the structure satisfies equal displacement rule). Therefore, $\mu_{e}$ is called nominal displacement ductility demand.

Latin American Journal of Solids and Structures 11(2014) 075 - 091 


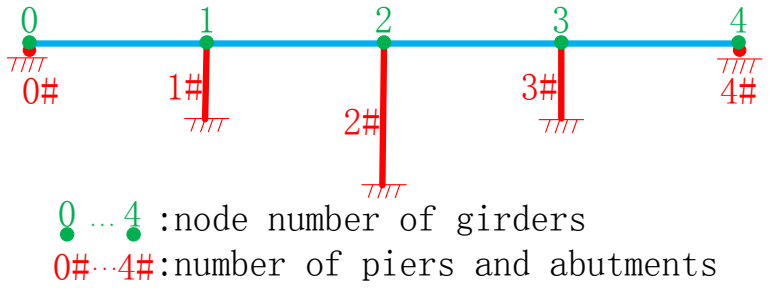

Figure 3 Typical continuous bridges

Table 1 Section properties of girder and piers

\begin{tabular}{cccccc}
\hline \hline Components & $\begin{array}{c}\text { Area } \\
\left(\mathbf{m}^{\mathbf{2}}\right)\end{array}$ & $\begin{array}{c}\text { Moment of } \\
\text { inertial }\left(\mathbf{m}^{\mathbf{4}}\right)\end{array}$ & $\begin{array}{c}\text { Polar moment } \\
\text { of inertia }\left(\mathbf{m}^{\mathbf{4}}\right)\end{array}$ & $\begin{array}{c}\text { Concrete } \\
\text { type }\end{array}$ & $\begin{array}{c}\text { Longitudinal reinforcement } \\
\text { steel and area ratio }\end{array}$ \\
\hline Girder & 7 & 40 & 14 & C50 & - \\
Column & 2.25 & 0.422 & 0.722 & C30 & HRB335, $0.66 \%$ \\
\hline \hline
\end{tabular}

\subsection{Earthquake excitation}

Earthquake load adopts elastic response spectrum for soil profile III in Chinese criteria (JTJ 00489 as shown in Fig.4 (Yang et al. 1989). It can be used for RSA to obtain the elastic displacement of structures.

Based on the elastic response spectrum, seven artificial motions are generated by Simqke procedure as for ground motion input of NTHA to obtain the inelastic displacement of structures (Fahjan and Ozdemir, 2008), and the average results of NTHA are regarded as the benchmark for comparison with RSA. One representative ground motion out of seven is shown in Fig.5. Other motions are not presented due to the similarity to Fig. 5.

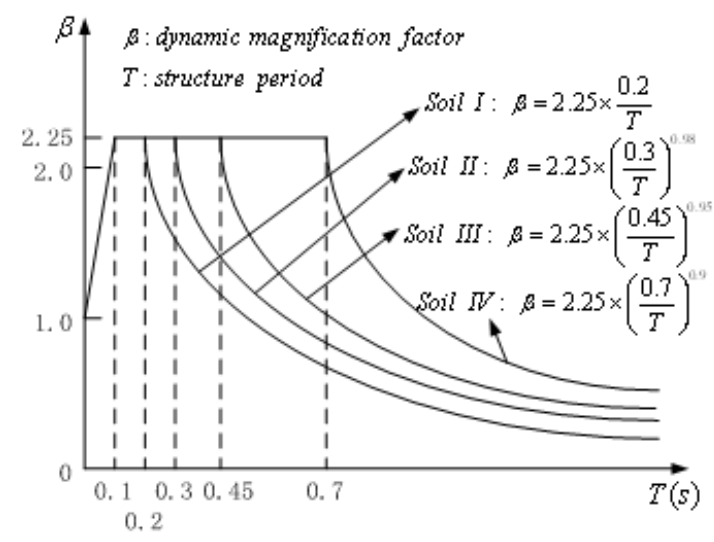

Figure 4 Elastic response spectrum for soil profile I, II, III, IV 


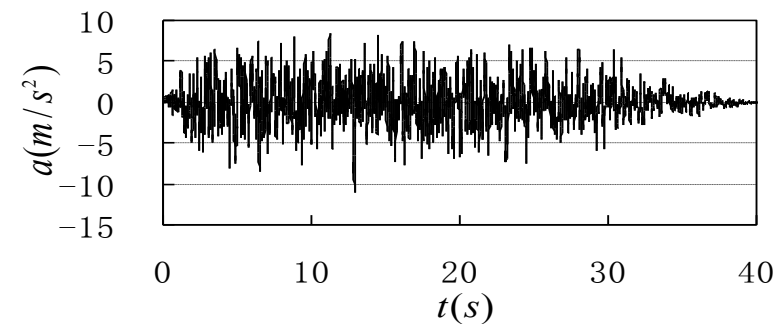

Figure 5 Ground motion time history $(P G A=1.1 \mathrm{~g})$ of soil type III

\subsection{Analyzing procedure}

As for continuous bridges, $T_{l}$ can be obtained by substituting the maximum nominal displacement ductility demand $\mu_{e m}$ of piers into Eq.(2). The phenomenon, that the displacement obtained from NTHA is very close to that of RSA when the minimum period $T_{\min }$ of main modes is no less than the foregoing $T_{l}$, is often found in traditional design. The following sections is targeting to validate this phenomenon.

Three cases of continuous bridges with various piers height combinations are identified as the baseline configuration, where shapes and section properties of girders and piers are shown in Fig.3 and Table 1 respectively. Heights of piers of these cases are chosen as $5 \mathrm{~m}-10 \mathrm{~m}-5 \mathrm{~m}, 10 \mathrm{~m}-5 \mathrm{~m}-10 \mathrm{~m}$ and $5 \mathrm{~m}-5 \mathrm{~m}-5 \mathrm{~m}$ respectively. Based on the three cases, some parameters are subjected to change to consider more combinations as shown in Table 2, and the combination rule is that one parameter is changed by keeping the others the same. As the three cases are the simplified model of the real bridges, the new models of Table 2 obtained by changing only one parameter are reasonable to include many practical bridges, and can be used for numerical simulation.

Table 2 Changing parameters of girder, piers and ground motion

\begin{tabular}{ccc}
\hline \hline Member type & Variables & Parameter values \\
\hline Girder & Lateral moment of inertia $\left(\mathrm{m}^{4}\right)$ & $20,40,80,160$ \\
& Polar moment of inertia $\left(\mathrm{m}^{4}\right)$ & $7,14,28,56$ \\
& Section area $\left(\mathrm{m}^{2}\right)$ & $3.5,7,14,28$ \\
& Single span length $(\mathrm{m})$ & $20,40,80,160$ \\
\hline Pier & Section area $\left(\mathrm{m}^{2}\right)$ & $1.0 \times 1.0 \mathrm{~m}, 1.5 \times 1.5 \mathrm{~m}, 2.0 \times 2.0 \mathrm{~m}$ and $2.5 \times 2.5 \mathrm{~m}$ \\
& Area ratio of longitudinal rein- & $0.4 \%, 0.8 \%, 1.2 \%$ and $1.6 \%$ \\
& forcement & pier2\# varies as $5,10,15 \mathrm{~m}$, while pier1\# equals to \\
& Height distribution of piers & pier 3\# and varies as $5 \mathrm{~m}, 10 \mathrm{~m}, 15 \mathrm{~m}$ and $20 \mathrm{~m}$ synch- \\
& & ronously \\
\hline Ground motion & Soil type & I, II, III and IV (See Fig.4) \\
\hline \hline
\end{tabular}

Based on table 2, a majority of cases are identified as irregular bridges which are mainly controlled by at least two main modes, and some other cases belong to regular bridge configuration 
which is governed soley by the fundamental mode. Regardless of irregular bridges or regular bridges, the sum of main modes participation mass factors of each model should be not less than $90 \%$ when dynamic analysis is performed, otherwise the corresponding results of RSA will not be reasonable. Furthermore, the minimum period of the main modes, the sum of whose participation mass factors is just beyond $90 \%$, is defined to be $T_{\min }$.

As for each scenario, two different analysis methods are implemented as follows:

(1) RSA was performed by using Opensees software (Mazzoni et al. 2007) with the piers simulated by elastic element, and the pier's initially elastic stiffness adopts the equivalent stiffness.

(2) NTHA was also conducted in Opensees analyzing program, in which the piers are simulated by fiber element, where the concrete is simulated by material Concrete02 and the steel is simulated by material Steel02.

\subsection{Numerical results}

For each bridge model, the peak ground acceleration (PGA) need to be adjusted accordingly to ensure the target $\mu_{e m}$ as of being 1.5, 3.0 and 6.0. As for each $\mu_{e m}$ and girder node of bridge cases shown in Fig.3, the displacement correction factor $C$ is calculated through dividing the displacement of NTHA by the displacement of RSA, and is summarized in scatter plots as shown in Fig.6. Since each bridge has five girder nodes as shown in Fig.3, there are five black dots of $C$ according to one $T_{\min }$, which is the minimum period of the main modes for one bridge. In case of symmetry, two black dots of $C$ will be covered by the corresponding symmetrical dots, and only three black dots of $C$ can be seen in Fig.6 according to one $T_{\min }$.

As for each $\mu_{e m}, T_{\min }$ is substituted into Eq.(1) to obtain the displacement correction factor $C$, and the curve of $C$ is expressed by red line as shown in Fig.6, which is used to judge if it can capture the distribution features of black dots of $C$.

In addition, the limiting period $T_{l}$ of equal displacement rule is obtained by substituting $\mu_{e m}$ into Eq.(2), and is expressed by green line as shown in Fig.6. As for each $\mu_{e m}$, the green line of $T_{l}$ divides the black dots of $C$ into two groups, including the left group wherein $T_{\min }$ is less than $T_{l}$, and the right group in which $T_{\min }$ is larger than $T_{l}$. The green line of $T_{l}$ helps to examine what the dispersion of the black dots of $C$ is relative to 1.0 when $T_{\min } \geq T_{l}$.

Characteristics of the irregular continuous bridges regarding the maximum nominal displacement ductility demand $\mu_{e m}$, the displacement correction factor $C$, the minimum period $T_{\min }$ of main modes and the limiting period $T_{l}$ can be observed and summarized from Fig. 6 as follows:

(1) For each $\mu_{e m}$, despite of the dispersion of the black dots of $C$, the associated $C$ curves in Fig. 6 (a), (b), and (c) is able to capture the distribution features of the black dots of $C$, which verifies that Eq.(1) of $C$ is meaningful and useful, and Eq.(2) of $T_{l}$ obtained by Eq.(1) is reasonable.

(2) For the same $\mu_{e m}$, the dispersion of the black dots of $C$ relative to the curve of $C$ increases,

as $T_{\min }$ decreases; for the same $T_{\min }$, the dispersion of the black dots of $C$ relative to the curve of 
$C$ increases, as $\mu_{e m}$ increases. Therefore, the distribution of the black dots of $C$ mainly depends on $T_{\min }$ and $\mu_{e m}$, and the influence of other factors is relatively small and can be neglected.

(3) For each $\mu_{e m}$, most of the black dots of $C$ lie between 0.8 and 1.2 when $T_{\min }$ is not less than the associated $T_{l}$, and the number of the black dots of $C$ beyond the range increases as $\mu_{e m}$ increases.

The abovementioned characteristics show that equal displacement rule is still applicable to the MDOF continuous bridges in the transverse direction when $T_{\min }$ is not less than $T_{l}$, and is defined as equal displacement rule of MDOF.

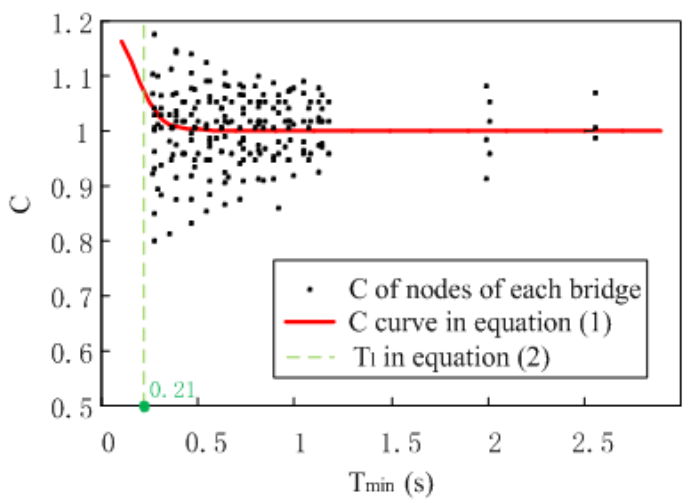

(a). $\mu_{e m}=1.5$

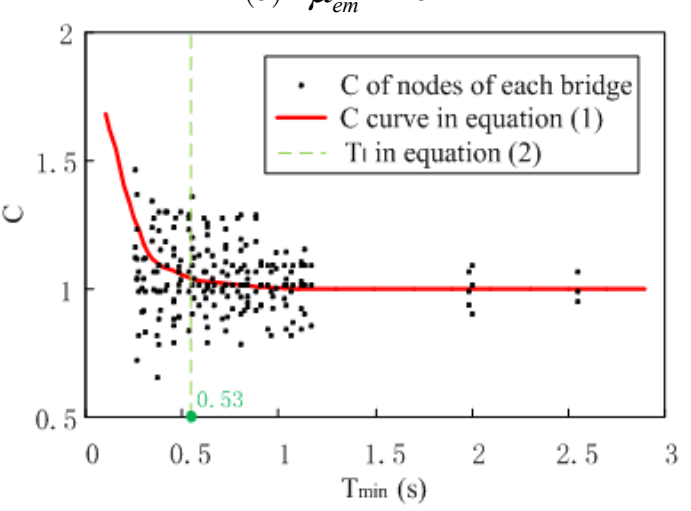

(b). $\mu_{e m}=3.0$

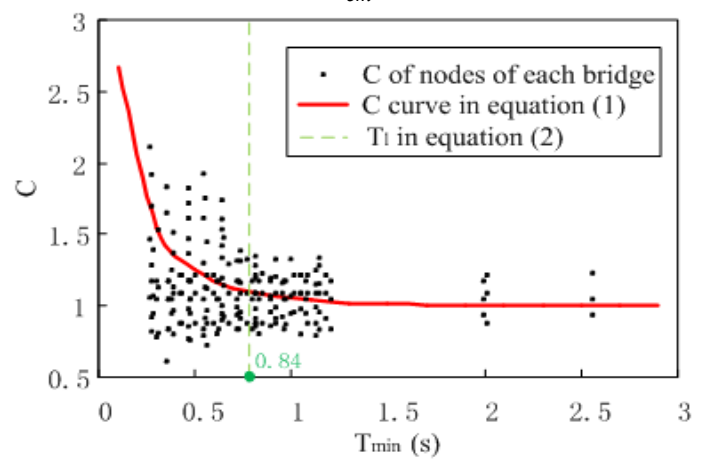

(c). $\mu_{e m}=6.0$ 
Figure 6 Distribution map of displacement correction factor $\mathcal{C}$

As equal displacement rule of MDOF is based on the analyses, for all of the continuous bridges with $T_{\min } \geq T_{l}$, the calculation precisions of equal displacement rule of MDOF are different. Fig.5 shows that as the minimum period $T_{\min }$ of main modes increases and the displacement ductility demand $\mu_{e m}$ decreases, the displacement correction factor $C$ of each bridge is closer to 1.0, and the changing trend is gradual. Therefore, it is some arbitrary to select $T_{\min } \geq T_{l}$ as the application condition of equal displacement rule of MDOF. As for all bridges with $T_{\min } \geq T_{l}$, if $T_{\min }$ is more larger than $T_{l}$, the calculation precision of equal displacement rule of MDOF will be better, contrarily will be worse.

Furthermore, when one structure enters into some level of ductility, the subtle change of the experimental model will produce obviously different displacement. In fact, any analytical methods won't be able to accurately predict the real elastoplastic displacement, including RSA, ITHA, and other methods. However, the results of these theoretical methods can envelop the possible displacement response of the structure. Therefore, as for the seismic design of the structure, especially when the structure's ductility demand is relatively high, it is unnecessary to pay excessive attention to the calculation precision of the theoretical methods. To this extent, the calculation errors of equal displacement rule of MDOF are not highly sensitive.

\section{EQUAL DISPLACEMENT RULE OF BRIDGES WITH LONG PERIODS}

Section three has extended equal displacement rule of SDOF to MDOF. Previous section shows that the limiting period $T_{l}$ is only related to the maximum nominal displacement ductility demand $\mu_{e m}$ of piers. If $\mu_{e m}$ is substituted by the displacement ductility capacity $\mu_{\Delta}$ of piers, the derived $T_{l}$ corresponds to the maximum value related to the maximum allowable level of damage of one bridge. Therefore, , equal displacement rule can be applied to any allowable level of damage of the bridge provided that $T_{\min } \geq T_{l}$. As for the piers of general continuous bridges, this section will discuss the maximum allowable damage level, and identify the maximum envelop $T_{l 1}$ of the limiting period $T_{l}$. Finally, as for the long period bridges, this section will simplify the application of equal displacement rule of MDOF.

\subsection{Exact formulation of the displacement capacity of piers and the limiting period}

In terms of the general continuous bridges, the shortest pier's displacement ductility capacity $\mu_{\Delta}$ is usually the largest, and thereby it controls the determination of $T_{l}$. As the height of the shortest pier of one bridge increases, its displacement ductility capacity $\mu_{\Delta}$ and the associated $T_{l}$ in Eq.(2) decreases, and moreover, $T_{\min }$ of the bridge increases accordingly. If $T_{\min } \geq T_{l}$, equal displacement rule can be applied to any allowable level of damage of the bridge.

The yield displacement of pier is given by 


$$
\Delta_{y}=\frac{1}{3} \phi_{y} H^{2}
$$

in which $H$ is the height of pier, $\phi_{y}$ is the yield curvature of pier's section and it can be calculated by (Tang et al. 2008 ; Kowalsky, 1997)

$$
\phi_{y}=\frac{a \varepsilon_{y}}{D}
$$

where $D$ is the section height in the calculated direction of pier, $\varepsilon_{y}$ is the yield strain of longitudinal reinforcement, the shape factor $a$ is 2.213 for circular section and 1.957 for rectangular section.

The displacement capacity $\Delta_{u}$ is expressed as (Tang et al. 2008) :

$$
\Delta_{u}=\frac{1}{3} \phi_{y} H^{2}+\left(\phi_{u}-\phi_{y}\right) H_{p}\left(H-0.5 H_{p}\right) / K
$$

where $H_{p}$ is the equivalent analytical plastic hinge length, $K$ is the safety factor of ductility, and $\phi_{u}$ is the ultimate curvature capacity of pier's section evaluated by (Kowalsky, 1997)

$$
\phi_{u}=\frac{\varepsilon_{c}}{D\left(b_{1}+b_{2} \gamma\right)}
$$

in which $\gamma$ is the axial compression ratio of pier's section; $b_{1}$ and $b_{2}$ are shape factors, which are equal to 0.162 and 0.665 for circular section, and 0.1094 and 0.829 for rectangular sectionrespectively; $\varepsilon_{c}$ is the ultimate compression strain of concrete shown as (Tang et al. 2008)

$$
\varepsilon_{c}=0.004+\frac{1.4 \rho_{s} f_{y h} \varepsilon_{s u}^{\prime}}{f_{c c}{ }^{\prime}}
$$

where $\varepsilon_{s u}^{\prime}$ is the ultimate tensile strain of stirrup with a typical value of $0.09, \rho_{s}$ is the ratio of volume of stirrup to the core volume of concrete, $f_{c c}{ }^{\prime}$ is the confined compressive strength of concrete, $f_{y h}$ is the yield stress of stirrup.

$H_{p}$, in Eq. (6), is the least value of the two equations followed by (Tang et al. 2008)

$$
\begin{gathered}
H_{p}=0.08 H+0.022 f_{y} d_{s} \geq 0.044 f_{y} d_{s} \\
H_{p}=\frac{2}{3} D_{\min }
\end{gathered}
$$


where $f_{y}$ is the yield stress of longitudinal reinforcement, $d_{s}$ is the bar diameter of longitudinal reinforcement, $D_{\min }$ is the least cross sectional dimension of pier.

Combing those equations, the displacement ductility capacity $\mu_{\Delta}$ of pier can be expressed by

$$
\mu_{\Delta}=\frac{\Delta_{u}}{\Delta_{y}}=\frac{\frac{1}{3} \phi_{y} H^{2}+\left(\phi_{u}-\phi_{y}\right) H_{p}\left(H-0.5 H_{p}\right) / K}{\frac{1}{3} \phi_{y} H^{2}}=1+\frac{3}{K}\left(\frac{\phi_{u}}{\phi_{y}}-1\right) \frac{H_{p}}{H}\left(1-0.5 \frac{H_{p}}{H}\right)
$$

Since Eq.(9) is generally applicable to any continuous bridges, substituting Eq.(5), (7) and (9) into Eq.(11) makes

$$
\mu_{\Delta}=1+\frac{3}{K}\left(\frac{\varepsilon_{c}}{a \varepsilon_{y}\left(b_{1}+b_{2} \gamma\right)}-1\right)\left(0.08+\frac{0.022 f_{y} d_{s}}{H}\right)\left(0.96-\frac{0.011 f_{y} d_{s}}{H}\right)
$$

substituting Eq.(5), (7) and (10) into Eq.(11)

$$
\mu_{\Delta}=1+\frac{3}{K}\left(\frac{\varepsilon_{c}}{a \varepsilon_{y}\left(b_{1}+b_{2} \gamma\right)}-1\right) \frac{2 D_{\min }}{3 H}\left(1-\frac{D_{\min }}{3 H}\right)
$$

Eq.(12) represents the displacement ductility capacity of pier in which $H_{p}$ is controlled by $H$, and is applicable to the bridges with dumpy piers. Eq.(13) represents the displacement ductility capacity of pier in which $H_{p}$ is governed by $D_{\min }$, and is applicable to the bridges with slender piers. Substituting Eq.(12) or (13) into Eq.(2)

$$
T_{l}=0.4529 \ln \mu_{\Delta}+0.0323
$$

Eq.(14) represents the limiting period of equal displacement rule when the piers are subjected to the damage level of maximum allowable inelastic deformation. To be conservative, the parameters in Eq.(12), (13) and (14) need to be analyzed and chosen such that $T_{l}$ could be achieved as large as possible, and $T_{l 1}$ provides the boundary of $T_{l}$. Therefore, all the general continuous bridges under the condition that $T_{\min } \geq T_{l 1}$ satisfy equal displacement rule.

\subsection{Analyzing procedure}

In order to ensure the largest possible value of $T_{l}$, it is adviced to choose the parameters in Eqs.(12-14) as follows:

(1) In Eq.(8), stirrup usually uses R235 with the ratio $\rho_{s}$ between 0.004 and 0.01 (Tang et al. 2008), and concrete type usually adopts C30, C35 and C40, thus the results of $\varepsilon_{c}$ are shown in 
Fig.7. Based on Eqs.(12-14), $T_{l}$ increases as $\mathcal{E}_{c}$ increases. As to obtain large value of $T_{l}, \mathcal{E}_{c}$ can conservatively adopt 0.015 in structural designs.

(2) Based on Eqs.(12-14), $T_{l}$ increases as $\gamma$ decreases, and $\gamma$ can conservatively adopt 0.1 in analysis.

(3) The longitudinal reinforcement usually uses HRB335 with $d_{s}$ between $0.016 \mathrm{~m}$ and $0.038 \mathrm{~m}$. $d_{s}$ adopts $0.028 \mathrm{~m}$ temporarily in analysis, and will be further discussed in the following text.

(4) in particular, $K$ is set to 2.0 according to Chinese criteria (Tang et al. 2008).

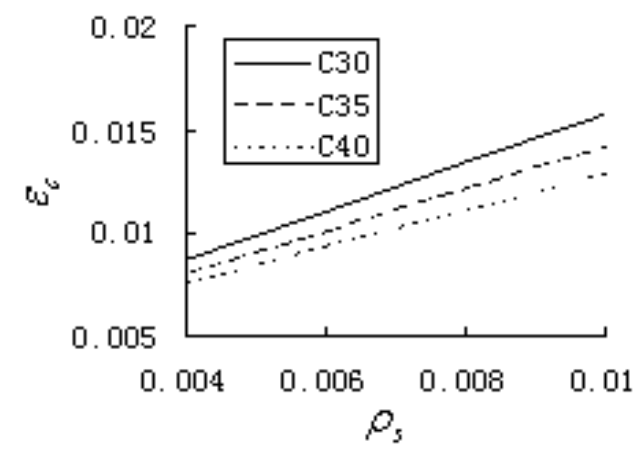

Figure 7 The ultimate compression strain $\varepsilon_{c}$ influenced by concrete strength and the ratio $\rho_{s}$

For a typical bridge structure, where $H$ ranges from $2.5 \mathrm{~m}$ to $30 \mathrm{mand} H / D_{\text {min }}$ is between 2.5 and 10, the developing trend of limiting period $T_{l}$ in terms of pier height is depicted in Fig. 8, considering two different pier cross section, namely cicular and retangular. In this figure, the black curve represents the relations between $T_{l}$ and $H$ as appeared in Eqs.(12) and (14), and the color lines represent the relations between $T_{l}$ and $H / D_{\min }$ indicated in Eqs.(13-14). From Fig.8, some observations are concluded as follows:

(1) $T_{l}$ decreases, as $H$ and $H / D_{\min }$ increase.

(2) When $H / D_{\min } \leq 4.0$, the color lines are all located above the black curve, and $T_{l}$ is controlled by $H$; for $H / D_{\min } \geq 8.0$, the color lines are all below the black curve, and $T_{l}$ is governed by $H / D_{\min }$; for $4.0<H / D_{\min }<8.0$, the color lines and the black curve are crossed, and $T_{l}$ may be controlled by $H$ or $H / D_{\min }$, which depends on the value of $H$ and $H / D_{\min }$.

Note that the foregoing dividing point of $H / D_{\min }$ is based on $d_{s}=0.028 m$, and will be different for other $d_{s}$. However, in spite of $d_{s}$, the maximum value of $T_{l}$ is always controlled by $H$, and is obtained when $\gamma$ and $H$ are the least. In Fig.8, when $\gamma=0.1$ and $H=2.5 m$, the maximum value of $T_{l}$ adopts $0.74 \mathrm{~s}$ for the circular section of pier, and $0.84 \mathrm{~s}$ for the rectangular section of pier.

Latin American Journal of Solids and Structures 11(2014) 075 - 091 


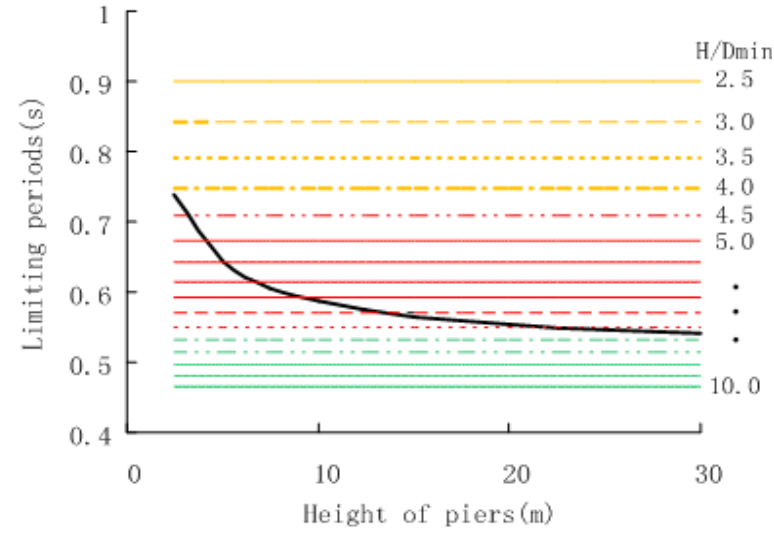

(a) Circular section

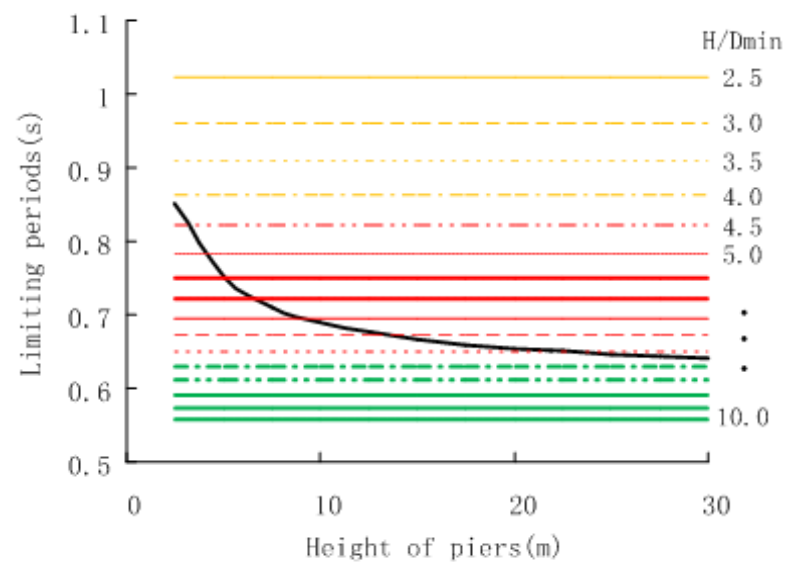

(b) Rectangular section

Figure 8 The relations between $T_{l}$ and $H$, and between $T_{l}$ and $H / D_{\min }$

\subsection{Numerical results}

The previous discussion shows that for the general continuous bridges, when $\gamma=0.1$ and $H=2.5 \mathrm{~m}, T_{l}$ will attain the maximum value, and will be subjected to changes as $d_{s}$ varies. Its relationship is shown in Fig.9, indicating that the maximum value of $T_{l}$ will be amplified as $d_{s}$ increases.

In routine designs, when $\gamma$ and $H$ are all small, the area ratio of longitudinal reinforcement and $d_{s}$ are usually small. Therefore, the maximum envelop $T_{l 1}$ of the limiting period $T_{l}$ can conservatively adopt the value of $T_{l}$ when the rectangular section adopts $d_{s}=0.02 \mathrm{~m}$, and $T_{l 1}=0.8 \mathrm{~s}$.

From Fig. $9, T_{l 1}=0.8 \mathrm{~s}$ not only envelops the maximum value of $T_{l}$ of all of the bridges with circular section piers, but also is 0.89 times the maximum envelope of $T_{l}$ of the bridges with rectangular section piers. Therefore, $T_{l 1}=0.8 \mathrm{~s}$ is relatively reliable.

Note that the foregoing $T_{l 1}$ is based on $K=2.0$ according to Chinese criteria (Tang et al. 2008). Furthermore, as for different criteria, $K$ can adopt different values, and then different $T_{l 1}$ are obtained. For example, the relation between the maximum value of $T_{l}$ and $d_{s}$ associated with $K=1.0$ is also drawn in Fig.9, and the maximum envelop $T_{l 1}$ can adopt 1.05s.

In spite of different values of $T_{l 1}$ according to different criteria, if $T_{\min } \geq T_{l 1}$, equal displacement rule can be applied to any allowable level of damage of the bridge. Note that the $\mu_{e m}$ related to $T_{l 1}=0.8 \mathrm{~s}$ in Eq.(2) is 5.45. As for the well designed bridge, based on design experience and model test, the maximum allowable level of damage generally adopts $\mu_{e m}=3 \sim 6$. Therefore, 
$\mu_{e m}=5.45$ is a relatively large value, and the corresponding $T_{l 1}=0.8 \mathrm{~s}$ is very conservative and reliable.

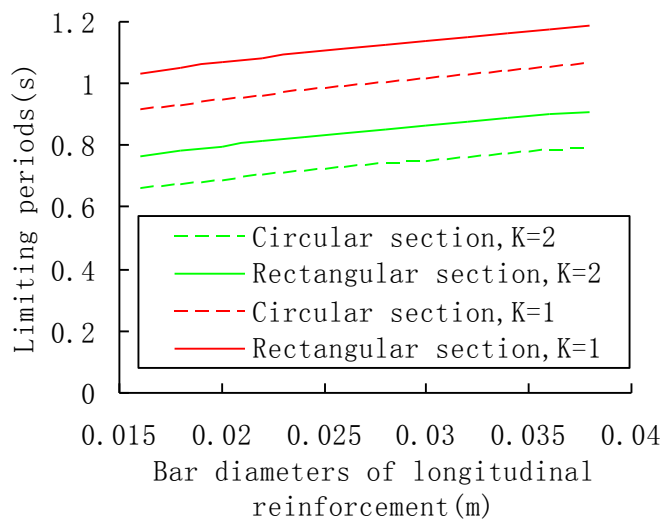

Figure 9 The relation between $T_{l}$ and $d_{s}$

\section{CONCLUSIONS AND DISCUSSIONS}

In this paper, the application of equal displacement rule is advanced into MDOF systems (e.g., continuous bridges)through a comprehensive parametric study of the ratio of maximum inelastic displacement to maximum elastic displacement for a typical continuous bridge, which is subjected to earthquake excitation in the transverse direction. The complete analysis procedure is documented in flow chart, as shown in Fig.10. It confirms that bridges with long periods inherently satisfy equal displacement rule. Furthermore, it provides a special insight to the bridges in the shortperiod range, and these bridges may potentially meet with equal displacement rule. Therefore, the following conclusions can be drawn:

(1) The limiting period predominately depends on the maximum nominal displacement ductility demand of piers. As the maximum nominal displacement ductility demand increases, the limiting period increases.

(2)Provided that the periods of bridge main modes are beyond the limiting period and the sumation of each mass participation factor is not less than $90 \%$, equal displacement rule can be applied for the bridge within the specified inelastic deformation level. According to Fig.10, the equal displacement rule criteria $\left(T_{\min } \geq T_{l}\right)$, mainly tailored towardsthe short periods bridges, can be used for all continuous bridges in principles from previous analysis.

(3) As for the bridge with long period, the application condition of equal displacement rule is further simplified based on the fact that the displacement ductility capacity $\mu_{\Delta}$ of piers and the corresponding limiting period $T_{l}$ are the only governing parameters. When the bridge structure becomes more flexible such that $T_{\min }$ is above the upper bound of the limiting period $T_{l 1}$, equal displacement rule can be applied to any allowable level of damage of the bridge. Herein the appli-

Latin American Journal of Solids and Structures 11(2014) 075 - 091 
cation condition of equal displacement rule can be treated as the traditional equal displacement rule.

Note that a special case $T_{l}>T_{\min } \geq T_{l 1}$ may exist under the strong motion shaking, where the maximum nominal displacement ductility demand $\mu_{e m}$ of the pier is larger than the displacement ductility capacity $\mu_{\Delta}$ and $T_{l}$ controlled by $\mu_{e m}$ in Eq.(2) could be possibly larger than $T_{l 1}$. Although the thorough investigation of this scenario is out of scope of this paper, one still could utilize the proposed procedure as described in Fig. 10 to determine the applicability of the equal displacement rule. The inelastic displacement obtained by RSA may be not true, but the corresponding displacement ductility demand will be larger than the displacement ductility capacity due to $T_{l}>T_{l 1}$. As a result, the bridge is not qualified to resist seismic load, and it should be redesigned or revised. Therefore, equal displacement rule is applicable to any bridge with $T_{\min } \geq T_{l 1}$, and the expression and application of equal displacement rule are fairly simple to follow.

In order to maitain the calculation precision of equal displacement rule, $T_{l 1}$ is usually adjusted to achieve the largest posible value via selecting appropriate parameters of piers in the previous analysis. Thus, a lot of continuous bridges with relatively short periods will not meet the condition $T_{\min } \geq T_{l 1}$. To ensure the applicability of the rule under this particular circumstance, $T_{l}$ is calculated by the basic equation Eq.(2), and the short-period bridge can use equal displacement rule if $T_{\min } \geq T_{l}$. Furthermore, as to change the calculation precision of equal displacement rule, the basic equation Eq.(2) of $T_{l}$ can also beupdated based on $C$, which is equal to 1.02, 1.05, 1.07 or other equivalent valuesdepending on the acceptant level of calculation precision To sum up, the extended equal displacement rule shown in Fig.10 is more all-round and useful than the traditional equal displacement rule, and can be implemented to assess the seismic performance of continuous bridge with either long period or short period.

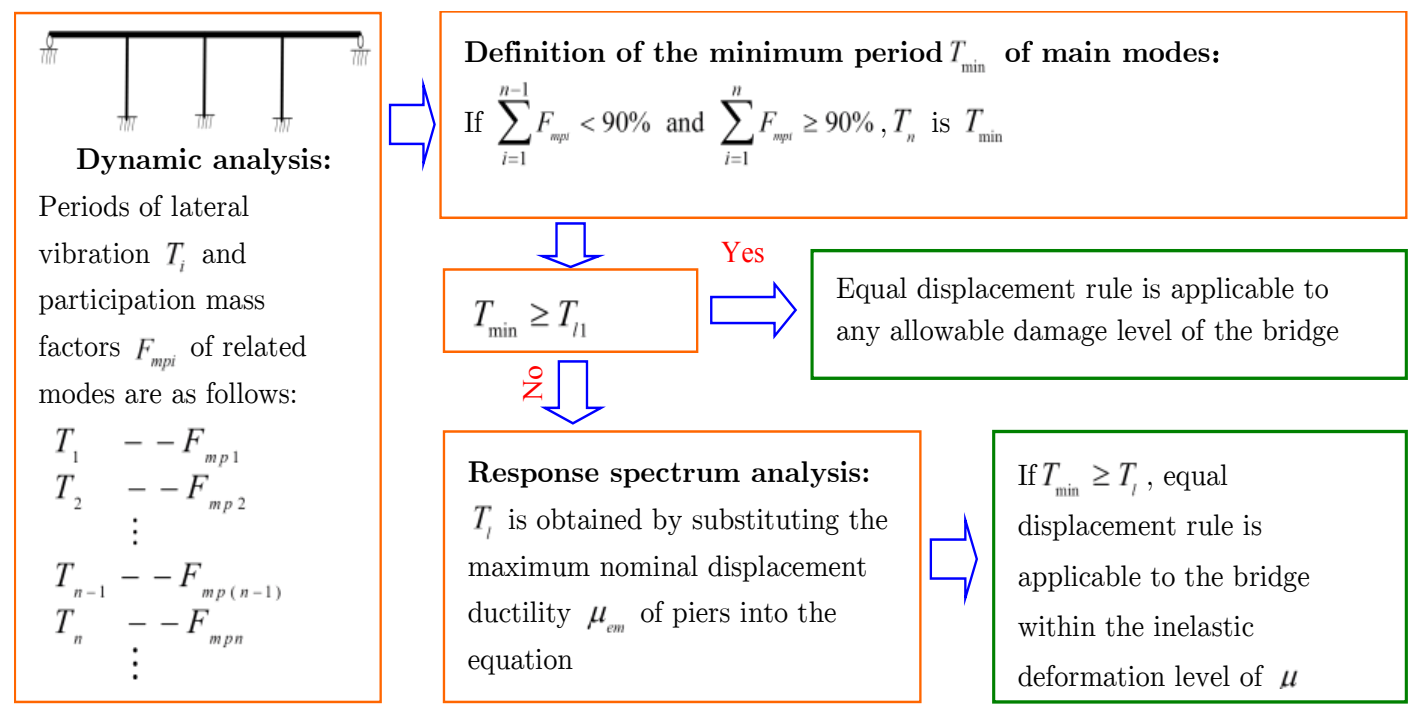

Figure 10 Procedure of equal displacement rule 
Acknowledgements This research is jointly supported by the China postdoctoral science foundation under grant No. 2011M500983, postdoctoral science foundation of central south university , and freedom explore program of central south university under grant No. 2012QNZT047. The above support is greatly appreciated.

\section{References}

Akhaveissy, A. H. (2012). Finite element nonlinear analysis of high-rise unreinforced masonry building. Latin American Journal of Solids and Structures 9(5):547-567.

Bayat, M., Abdollahzadeh, G. (2011). On the effect of the near field records on the steel braced frames equipped with energy dissipating devices. Latin American Journal of Solids and Structures 8(4):429-443.

Chopra, A. K, Goel, R. K. (2002). A modal pushover analysis procedure for estimating seismic demands for buildings. Earthquake Engineering and Structural Dynamics 31(3):561-582.

Clough, R. W., Penzien, J. (2003). Dynamics of structures. New York: Mc Graw-hill, Inc.

Fahjan, Y., Ozdemir, Z. (2008). Scaling of earthquake accelerograms for non-linear dynamic analysis to match the earthquake design spectra. The 14th World Conference on Earthquake Engineering, Beijing, China.

Isakovic, T., Fischinger, M. (2006). Higher modes in simplified inelastic seismic analysis of single column bent viaducts. Earthquake Engineering and Structure Dynamics 35(1):95-114.

Jameel, M., Islam, A. B. M. S., Hussain, R. R., et al. (2013). Non-linear FEM analysis of seismic induced pounding between neighbouring multi-storey structures. Latin American Journal of Solids and Structures 10(5):921-939.

Kowalsky, M. J. (1997). Direct displacement-based design: a seismic design methodology and its application to concrete bridges. PhD thesis, University of California, San Diego, San Diego, Calif.

Kowalsky, M. J. (2002). A displacement-based approach for the seismic design of continuous concrete bridges. Earthquake Engineering and Structure Dynamics 31(3):719-747.

Mazzoni, S., McKenna, F., Scott, M., H., et al. (2007). OpenSees Command Language Manual. Pacific Earthquake Engineering Research, California.

Miranda, E. (2000). Inelastic displacement ratio for structures on firm sites. Journal of Structural Engineering 126(10): 1150-1159.

Newmark, N. M., Hall, W. J. (1969). Seismic design criteria for nuclear reactor facilities. Proceedings of the 4th World Conference on Earthquake Engineering, Santiago, Chile 2: 37-50.

Riddell, R., Hidalgo, P., Cruz, E. (1989). Response modification factors for earthquake resistant design of short period structures. Earthquake Spectra 5(3): 571-590.

Tang, G. W., Li, J. Z., Tao, X. X., et al. (2008). Guidelines for Seismic Design of Highway Bridges. Beijing: China Communications Press.

Veletsos, A. S., Newmark, N. M. (1960). Effect of inelastic behavior on the response of simple systems to earthquake motions. Proceedings of the 2nd World Conference on Earthquake Engineering, Japan 2: 895-912.

Wang, Y. J., Wei, Q. C., Shi, J., et al. (2010). Resonance characteristics of two-span continuous beam under moving high speed trains. Latin American Journal of Solids and Structures, 7(2):185-199.

Wang, Y. J., Yau, J. D., Wei, Q. C. (2013). Interaction response of train loads moving over a two-span continuous beam. International Journal of Structural Stability and Dynamics, 13(1): 1350002.

Wei, B. (2011). Study of the applicability of modal pushover analysis on irregular continuous bridges. Structural Engineering International 21(2):233-237.

Yang, F. C., Chang, L., Fan, L. C., et al. (1989). Specifications of Earthquake Resistant Design for Highway Engineering. Beijing: China Communications Press.

Latin American Journal of Solids and Structures 11(2014) 075 - 091 
Xia, Y., Ma, H. Y., Su, D. (2013). Strain mode based damage assessment for plate like structures. Journal of Vibroengineering, 15(1): 37-45. 
